\title{
Estimates of Comparative Costs for Uprating Transmission Capacity
}

\author{
Ross Baldick, Fellow, IEEE, and Richard P. O'Neill
}

\begin{abstract}
In this paper, we estimate the costs of increasing transmission system capability through technologies for uprating transmission capacity without expanding the transmission footprint. We compare costs for uprating to the costs of new capacity.
\end{abstract}

Index Terms-Flexible AC transmission systems (FACTS), transmission assets.

\section{INTRODUCTION}

$\mathbf{I}$ NCREASING real-estate costs and continued opposition to new transmission lines make the construction of new transmission lines and the establishment of new transmission corridors difficult, particularly in urban areas. This paper estimates the costs, on a per megawatt-mile basis, of using various technologies to uprate transmission capacity without increasing the footprint of transmission.

Because of uncertainty about a number of details, estimates are only approximate. However, by denominating costs of all considered technologies on a per megawatt-mile basis and explicitly describing the basis for this analysis, we provide a framework for both generically comparing uprating technologies and also for more detailed analysis.

In Section II, we briefly review a standard model of transmission lines in the context of parameters that are relevant to uprating capacity. We then discuss capacity and operating costs. Section III then describes various ways to uprate the capacity of lines, with estimates of costs for uprating. Section IV briefly concludes. All costs in this paper are quoted in circa 2005 U.S. dollars. Since raw materials costs have increased significantly in the 2005 to 2008 timeframe, the results should be viewed primarily as estimates of relative upgrade costs, rather than absolute estimates.

\section{ModEl of AC TRANSMisSiON LiNES}

\section{A. Parameters Specifying Electrical Model and Characteristics}

In this section, we review the electrical model and characteristics of $\mathrm{AC}$ transmission lines, focusing on the issues most

\footnotetext{
Manuscript received December 28, 2007. First published February 18, 2009; current version published March 25, 2009. This paper does not necessarily reflect the view of the Federal Energy Regulatory Commission or any Commissioner. Paper no. TPWRD-00829-2007.

R. Baldick is with the Department of Electrical and Computer Engineering, The University of Texas at Austin, Austin, TX 78712 USA (e-mail: Ross.Baldick@engr.utexas.edu).

R. P. O'Neill is with the Federal Energy Regulatory Commission, Washington, DC 20426 USA (e-mail: Richard.oneill@ferc.gov).

Digital Object Identifier 10.1109/TPWRD.2008.2002990
}

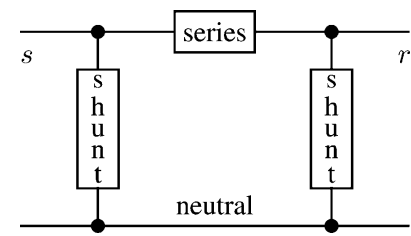

Fig. 1. Equivalent- $\pi$ circuit of per-phase equivalent of transmission line.

relevant to uprating of capacity. The material in the section is based, in part, on [1].

1) Admittance and Impedance: Fig. 1 shows an equivalent- $\pi$ model of a single-phase equivalent of a transmission line between buses $s$ and $r$ [1]. The series element consists of an inductance in series with a resistance. The resistance depends primarily on the resistivity of the conductor, the cross-sectional area of conductor, and the length of the line. The inductance depends primarily on the spacing of the conductors, the diameter of the conductors or bundles of conductors, and the length of the line. At nominal system frequency, the inductive reactance is typically much larger than the resistance, with this ratio increasing with increasing voltage. We will denote the series impedance by $R+j X$, where $R$ is the series resistance and $X$ is the inductive reactance.

The shunt elements consist of a capacitor in parallel with a small conductance. The shunt conductance primarily depends on the insulator string characteristics, the ambient air characteristics, and the length of the line. The capacitance primarily depends on the conductor spacing and the length of the line. Usually, the shunt conductance is negligible. We will denote the total shunt admittance by $G+j B$, where $G$ is the conductance and $B$ is the capacitive susceptance. The shunt element at each end of line has value $(1 / 2)(G+j B)$.

Table I shows distributed impedance per unit length and other data for typical transmission lines. The data in the table is excerpted from [1]. For some of the discussion concerning flexible AC transmission systems (FACTS) below (Section III-A-4), we will approximate the transmission model by a simplified model consisting of a single series inductive reactance, denoted by $X$. For a short line having negligible shunt capacitance and conductance, $X$ is well approximated by the product of the inductive reactance per unit length multiplied by the length. For longer lines, the relationship is more complicated [1, Ch. 4]. Qualitative results are similar for both the more accurate and the approximate model.

Fig. 2 shows such a simplified model together with phasor line-neutral voltage sources, $V_{s}$ and $V_{r}$, at the sending and receiving ends of the line. The neutral has been omitted from the figure. 
TABLE I

Line Data for Typical Transmission Lines. Source: Data Is EXcerpted From [1, TABle 3.1]

\begin{tabular}{||l|ccc||}
\hline & \multicolumn{3}{|c||}{ Line-to-line voltage $(\mathrm{kV})$} \\
Characteristic & 138 & 345 & 765 \\
\hline Thermal current-carrying capability per conductor $(\mathrm{A})$ & 770 & 1010 & 1250 \\
Conductors per bundle in each phase & 1 & 2 & 4 \\
Per-phase inductive reactance per unit length $(\Omega / \mathrm{mile})$ & 0.789 & 0.596 & 0.535 \\
Per-phase resistance per unit length $\left(\right.$ at $60 \mathrm{~Hz}$ and $\left.50^{\circ} \mathrm{C}, \Omega / \mathrm{mile}\right)$ & 0.1688 & 0.0564 & 0.0201 \\
Per-phase capacitive reactance per unit length $(\mathrm{M} \Omega / \mathrm{mile})$ & 0.186 & 0.142 & 0.129 \\
\hline
\end{tabular}

TABLE II

LiNe CAPACITIES BASED ON DATA IN TABLE I

\begin{tabular}{|c|c|c|c|}
\hline \multirow[b]{2}{*}{ Characteristic } & \multicolumn{3}{|c|}{ Line voltage $(\mathrm{kV})$} \\
\hline & 138 & 345 & 765 \\
\hline Three-phase thermal capacity (MW) & 184 & 1207 & 6625 \\
\hline Three-phase stability limit (100 mile length of line with $45^{\circ}$ angle limit) (MW) & 175 & 1450 & 8050 \\
\hline Three-phase stability limit (350 mile length of line with $45^{\circ}$ angle limit) (MW) & 50 & 415 & 2270 \\
\hline
\end{tabular}

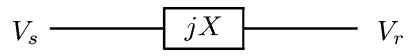

Fig. 2. Simplified circuit of per-phase equivalent of transmission line.

The complex phasor $I$ representing the line current flowing in the direction from sending to receiving end in Fig. 2 is given by:

$$
I=\left(V_{s}-V_{r}\right) /(j X)
$$

Denoting the magnitude of the sending and receiving end voltages by $\left|V_{s}\right|$ and $\left|V_{r}\right|$, respectively, and letting the difference in sending and receiving end phasor voltage angles be $\delta$ we obtain that the per-phase real power flow on the line is:

$$
P=\left|V_{s}\right|\left|V_{r}\right| \sin (\delta) / X
$$

while the reactive power flowing into the line at the sending end is $Q_{s}=\left|V_{s}\right|\left(\left|V_{s}\right|-\left|V_{r}\right| \cos (\delta)\right) / X$ and the reactive power flowing out of the line at the receiving end is $Q_{r}=\left|V_{r}\right|\left(\left|V_{r}\right|-\right.$ $\left.\left|V_{s}\right| \cos (\delta)\right) / X$. The factor $1 / X$ occurs in all these equations and we will refer to $1 / X$ as the magnitude of the line series admittance, which should not be confused with the line shunt admittance.

2) Losses: The current $I$ flowing in the line (1) produces electrical losses in the line resistance, $|I|^{2} R$, which heats the line. The heat is conducted, convected, and radiated to the environment and the temperature rise depends on the current flow and ambient conditions. For sending and receiving end voltages that are approximately constant, the current flow is approximately proportional to the magnitude of the complex power flow on the line, $\sqrt{P^{2}+Q^{2}}$, where $P$ is the real power flow on the line and $Q$ is the reactive power flow on the line. Consequently, losses are approximately proportional to $P^{2}+Q^{2}$. That is, losses depend approximately quadratically on power flow and are, therefore, highly variable with flow.

3) Thermal Capacity Limit: The rise in temperature due to current $I$ flowing on the line causes expansion of the line leading to both temporary and permanent changes in the line. The steady-state thermal power flow rating is determined by the temperature rise such that the permanent changes in the line are relatively small and such that the expansion of the line does not violate clearances between the line and other structures and trees. Table II shows three-phase thermal capacities based on the typical current carrying-capabilities in Table I, assuming voltage magnitudes are equal to their nominal rated values.

Although the capacities in Tables I and II are typical, thermal capacities depend on the ambient temperature and weather conditions. Consequently, thermal capacities are often specified by season, based on a maximum expected ambient temperature and a specification of weather conditions in each season. Capacities based on seasonal maximum expected temperatures will usually be conservative. A more precise time-varying estimation of the thermal capacity can be made based on actual weather and conductor temperature conditions. In particular, if actual conductor temperatures are measured and telemetered then real-time capacities can be calculated.

4) Voltage Limit: The transmission lines are suspended on insulator strings that have rated voltage capabilities. That is, the magnitudes $\left|V_{s}\right|$ and $\left|V_{r}\right|$ must remain below limits. If voltages get too low, on the other hand, there are other problems, including the potential for "voltage collapse" and of poor regulation of distribution system voltages. These limitations on the voltage magnitudes $\left|V_{s}\right|$ and $\left|V_{r}\right|$ can imply a limit on the flow of power on the line. In particular, off-line voltage stability studies may be used to establish proxy real or complex flow limits that, if respected, will prevent voltage collapse, at least for the particular conditions studied. Since a given flow of power on a line may correspond to a variety of voltage conditions, these proxy limits are likely to be poor representations of the true capability of the system.

5) Steady-State Stability Limit: Even in the absence of losses (and, therefore, in the absence of a thermal capacity limit) the power flow along the line in (2) is limited to a maximum of $\left|V_{s}\right|\left|V_{r}\right| / X$ at $\delta=\pi / 2$. For angles larger than $\pi / 2$, the power flow predicted by (2) decreases from its maximum value of $\left|V_{s}\right|\left|V_{r}\right| / X$. However, in reality for such angles the assumption of steady-state operation is violated: generation sources at either end of the line would lose synchronism, potentially causing damage to the generators and other assets. To avoid this situation, the angle across any line (and, more generally, between remote generation and load centers) is limited to well below $\pi / 2$, 
implying a limit on power flow that is proportional to the magnitude of the line series admittance $1 / X$ [2]. For example, a typical limit might require angle differences to be no more than $\pi / 4$. Table II shows stability limits for lines of length 100 miles and 350 miles, assuming an angle difference limit of $\pi / 4$.

6) Overload Capability: We consider the implications of overloading lines past thermal, voltage, and stability limits. Thermal overloads that result in exceeding the temperature rating of the line will reduce its lifetime, in principle incurring a cost due to re-conductoring at an earlier time. Moreover, clearances to structures and trees may be violated. Because of the thermal mass of the line, however, overloads for short periods can be tolerated without exceeding the temperature rating of the line or causing clearance violations. Transmission lines therefore have thermal ratings for both steady-state and for short times that are designed to avoid exceeding the temperature rating of the line and avoid violating clearances.

Proxy limits due to voltage stability may be conservative under many system conditions (and possibly optimistic under other system conditions) due to the rough correspondence between power flow and voltage conditions. There may be some opportunities to overload past these proxy limits, so long as voltage collapse issues are not relevant.

Overloading the line past its stability limit risks the loss of synchronism in the system. However, stability limits have historically been set fairly conservatively at values such as $\pi / 4$ so that there may be some scope for increasing the allowed angle differences across lines.

7) Non-Steady-State Phenomena: Subsequent to a line or generator outage or any other major change in the system, the system is no longer in steady-state (or quasi-steady-state) until the transient is damped out. To analyze such events, transient analysis of the interaction of lines and generators is necessary. The steady-state models no longer apply. We will not consider these issues in detail and assume that uprating of capacities do not cause non-steady-state phenomena to become problematic.

\section{B. Specific Capacity Costs of Existing Transmission}

To establish a context for evaluating the cost for uprating capacity, it is helpful to estimate the cost of existing transmission capacity. Costs vary significantly due to various issues besides the capacity of a line. For example, based on data filed at FERC for transmission lines in the U.S., [3] reports typical specific capacity costs in the range of:

- \$400/MW-mile to \$3000/MW-mile, including land and substation costs, for transmission lines operating at below $200 \mathrm{kV}$, and

- $\$ 400 / \mathrm{MW}$-mile to $\$ 1000 / \mathrm{MW}$-mile, including land and substation costs, for transmission lines operating at above $200 \mathrm{kV}$.

Transmission capacity costs are highly dependent on local issues such as land acquisition costs. Costs are generally higher for shorter lines because substation costs tend to be fixed independent of the length of the line.

Data in [4] for $132 \mathrm{kV}$ transmission lines in New South Wales, Australia, suggest a specific capacity cost of around \$700/MWmile, apparently including land but not apparently including substation costs. Data in [5] for $138 \mathrm{kV}$ transmission lines in Colombia suggest a specific capacity cost of around \$500/MWmile, including land and substation costs. Data in [5] for $220 \mathrm{kV}$ transmission lines in Colombia suggest a specific capacity cost of around \$200/MW-mile, including land and substation costs. Data in [6] for $500 \mathrm{kV}$ transmission, assuming a thermal capacity of $2500 \mathrm{MW}$, yields costs in the range of $\$ 130 / \mathrm{MW}$-mile to $\$ 400 / \mathrm{MW}$-mile. This international data is broadly consistent with the U.S. data, except that the Colombian and Brazilian data is somewhat lower than the low end of the U.S. typical range of costs.

\section{Operating Cost Function}

The main operating costs are the losses incurred in the line. Strictly speaking, these are of the form $|I|^{2} R$, where $I$ is the complex line current (1) and $R$ is the resistance. The loss function can be approximated as being quadratic in the magnitude of the complex power flow, $P^{2}+Q^{2}$.

\section{SCOPE FOR ChANGING OR UPRATING AC TRANSMISSION CAPACITY OR CHANGING PARAMETERS}

There are a number of ways to change the effective capacity of the line. Some of these technologies for uprating capacity, such as shunt and series compensation, phase-shifting transformers, and FACTS devices, primarily offer ways to better utilize thermal capacity of the line, in some cases by altering the transmission line parameters. That is:

- an investment in thermal capacity has already been made (and is sunk);

- the thermal capacity is not being fully utilized because of operational considerations; and

- further investment can increase the utilization of this capacity.

We will discuss these options for better utilizing existing thermal capacity in Section III-A.

Other technologies for uprating capacity, such as re-conductoring and line tensioning devices truly increase the effective thermal capacity. We will discuss these options for increasing thermal capacity in Section III-B.

For each technology, we characterize the effective uprating of capacity and we estimate the effective uprating cost, based on assumed specific costs for the technology and operational conditions that enable denomination of the effective uprating cost in terms of the specific cost of the upgrade. We will focus primarily on $345 \mathrm{kV}$ and $138 \mathrm{kV}$ lines and on a 100 mile length of line. These costs are summarized in Table III. Since they depend on a number of assumptions, they should be construed as being rough generic estimates.

\section{A. Increased Utilization of Thermal Capacity}

In this section, we will consider various ways to better utilize thermal capacity. We will roughly calculate the cost of achieving this better utilization by considering the increased flow on an otherwise under-utilized line. We will discuss these examples as though steady-state pre-contingency flows were the relevant issue; however, it should be understood that most systems are contingency-constrained. For a contingency-constrained system, we can interpret the examples as showing how 
to change post-contingency flows so as to better utilize the system.

1) Shunt Compensation: At medium and heavy power flows, transmission lines are net absorbers of reactive power. That is, reactive power consumption of the inductive part of the line exceeds the reactive power production of the capacitive part of the line.

If the receiving end of the line does not have a local reactive power source then the reactive power will be imported on the line from the sending end, which has two implications. First, the receiving end voltage will be lower, slightly reducing the capacity of the line since power flow at the receiving end is proportional to the receiving end voltage. Second, some of the capacity of the line will have been used to import reactive power. Shunt capacitor compensation can be used to provide this reactive power. By increasing the magnitude of the receiving end voltage, shunt compensation slightly increases the capacity of the line. More importantly, by reducing the transmission of reactive power, shunt compensation allows the thermal capacity of the line to be more fully utilized for real power transmission and helps to regulate the receiving end voltage of the line. (Shunt reactors absorb reactive power, which is sometimes necessary at low flow levels.)

Shunt compensation can be fixed or mechanically or electronically switched (see Section III-A-4), or a combination of these. Mechanically switched shunt compensation has specific costs of approximately \$10-50/kVAr [5], with higher costs at higher operating voltages. It may be designed to respond to changes in voltage levels or be based on the time of day. Generally, mechanically switched compensation is switched relatively infrequently to minimize wear and tear on the circuit breakers. For example, [7, p. 164] suggests a typical life of 2000 to 5000 operations, while [8, p. 247] suggests 1000 operations without maintenance and a lifetime with maintenance of 20000 operations.

To translate the specific cost of switched capacitors into a cost of uprating capacity, we must consider the effect of both real and reactive power on the line current. Consider, for example, a line transmitting both real power and reactive power at 0.9 power factor. (This example is based on [9].) For each kilowatt of real power transmitted, the line also transmits about $0.48 \mathrm{kVAr}$ of reactive power. Each additional $2 \mathrm{kVAr}$ of reactive power produced at the receiving end of the line would allow approximately an additional $1 \mathrm{~kW}$ to be delivered by the line. This reactive power could be provided by, for example, switched capacitors, local generation, or FACTS devices at the receiving end of the line.

We first consider the provision of this reactive power by switched capacitors. Assuming an installed specific cost of switched capacitors on the order of $\$ 10 / \mathrm{kVAr}$, switched capacitors to provide $2 \mathrm{kVAr}$ would cost about $\$ 20$, for an effective cost of real power capacity of about $\$ 20 / \mathrm{kW}$. Translated back into the context of a 100 mile length of line, the effective uprating cost is $\$ 200 / \mathrm{MW}-$ mile. For capacitors costing $\$ 50 / \mathrm{kVAr}$, the effective uprating cost would be $\$ 1000 / \mathrm{MW}$-mile. (See Table III for a summary of this and later effective uprating costs.)

As more reactive compensation is added, however, there are at least four countervailing issues. One is the possibility that volt- ages may become dangerously high under some transient conditions, particularly if capacitors are only occasionally switched or are not controlled in response to changes in the system. The significance of this effect depends on the capability of the circuit breakers or switches to sustain multiple operations and on the level of control of the capacitors. As mentioned, we have not quantified the costs of such control.

The second issue is that, in highly compensated systems, voltage instability can occur at relatively high voltages and proxy capacity limits may be a poor guide to the true capability of the system. The interaction between compensation and voltage instability is due to the fact that reactive power production by a capacitor is proportional to the square of the system voltage, so as voltage drops the reactive power from fixed capacitors decreases, which tends to further depress the voltage, promoting the sudden onset of voltage instability. That is, the "nose" of the voltage stability curve is sharpened with increased compensation. FACTS-based sources of reactive power, to be discussed in Section III-A-4, are less prone to this problem because reactive output can be quickly adjusted to help maintain voltage and avoid voltage instability. Consequently, high levels of compensation may require FACTS in addition to switched capacitors, increasing the overall cost of compensation.

The third issue is the possibility of "sub-synchronous resonance," which also affects series capacitor compensation to be discussed in Section III-A-2. The fourth issue is that as the power factor increases, more reactive compensation is needed for each kilowatt of increased utilization. In particular, for a 100 mile length of line, it is probably not worthwhile to increase its power factor above 0.97, given the cost assumptions in the previous paragraphs, for an overall increase in power flow of $5-10 \%$ over the uncompensated real power flow.

Longer lines and lines with a higher cost per megavolt-ampere-mile would justify higher levels of reactive compensation (absent voltage and sub-synchronous resonance issues), while shorter lines would justify less compensation. In much of North America, shunt compensation has already been utilized to increase the effective utilization of thermal capacity.

2) Series Compensation: If several lines are in parallel or roughly in parallel then the power flow on them will be shared in proportion to their respective series admittances. If these lines have differing ratios of thermal capacity to series admittance then the sharing of flows amongst them will not be in proportion to their thermal capacity. Consequently, as total flow increases, one line will reach its capacity before the others. Series compensation by capacitors of capacitive reactance $X_{C}$ allows the total series admittance of the line and compensation to be increased from $1 / X$ to $1 /\left(X-X_{C}\right)$, modifying (2) to [7, Sec. 6.1.1]:

$$
\left|V_{s}\right|\left|V_{r}\right| \sin (\delta) \frac{1}{X-X_{C}},
$$

which will increase the flow on the line for given sending and receiving end voltage magnitudes and given angle $\delta$. A series compensated line will take a greater proportion of the power flow on the parallel lines. Series compensation does not increase the capacity of the line; however, it allows the thermal capacity of the line to be more fully utilized for real power transmission. 
This can be useful for higher voltage lines that are roughly in parallel with lower voltage and capacity lines.

We consider adding a small amount of series capacitance having capacitive reactance $X_{C}$ to an initially uncompensated $345 \mathrm{kV}$ line under the assumption that prior to compensation the flows are somewhat less than the line's thermal capacity of 1207 MW, as specified in Table II. Ignoring changes in the voltage magnitudes, line current magnitude, and angles at the ends of the line, the flow on the line increases by a factor of:

$$
\begin{aligned}
\frac{1 /\left(X-X_{C}\right)}{1 / X} & =\frac{1}{1-X_{C} / X}, \\
& \approx 1+X_{C} / X, \text { for } X_{C} \ll X, \\
& =1+\left(|I|^{2} X_{C}\right) /\left(|I|^{2} X\right), \\
& =1+Q_{C} / Q_{X},
\end{aligned}
$$

where $Q_{X}$ is the reactive power absorbed by the line and $Q_{C}$ is the reactive power produced by the series compensation.

For a 100 mile length of $345 \mathrm{kV}$ line, the per-phase reactance is $X=59.6 \Omega$, using the value in Table I. Assuming that the line flow on the line is just somewhat below its thermal capacity, the initial uncompensated line current would be approximately equal to, but somewhat below, $1010 \mathrm{~A}$. The reactive power absorbed by the series reactance of the line would be about 182 MVAr. Consequently, series compensation of $Q_{C}$ would increase the flow on the line by $1207 \times Q_{C} / 182 \approx 6 Q_{C}$ MW/MVAr. For example, addition of 1 MVAr of series compensation would increase the real power flow by about $6 \mathrm{MW}$.

Series capacitors are more expensive than shunt capacitors because of the higher voltages they experience in fault conditions. A range of $\$ 15 / \mathrm{kVAr}$ to $\$ 60 / \mathrm{kVAr}$ may be reasonable for switched capacitors [5], [10, Table C-4-1]. Assuming a specific cost of $\$ 20 / \mathrm{kVAr}$ (based on the capacitance required to produce this amount of reactive power at rated line current), this yields an effective uprating cost of around \$3000/MW. Translated back into the context of the 100 mile length of line, the effective uprating cost is $\$ 30 / \mathrm{MW}$-mile.

However, this figure over-estimates the effect of series compensation at changing flows at lower flow levels because the increase in the flow due to the addition of capacitance is proportional to the uncompensated flow. Consequently, the effective uprating cost is proportionally larger. For example, at a pre-compensation flow of half the thermal capacity, the effective uprating cost is around $\$ 60 / \mathrm{MW}$-mile for a specific capacitor cost of $\$ 20 / \mathrm{kVAr}$ and around $\$ 180 / \mathrm{MW}$-mile for a specific capacitor cost of $\$ 60 / \mathrm{kVAr}$.

The effective uprating costs for longer lines would be proportionally smaller. This accounts for the greater prevalence of series compensation on longer lines, particularly those in the Western Interconnection of North America.

Unfortunately, series compensation by capacitors can have a significant drawback. The reason is that large generators have mechanical resonances with resonant frequencies corresponding to electrical frequencies in the range of a few tens of Hertz. The combination of capacitor and line inductance can have a resonant frequency that is close to this frequency, giving rise to the issue of sub-synchronous resonance, which is capable of damaging generators [7, Sec. 6.1.5]. This limits the application of fixed and mechanically switched series compensation. (FACTS devices can avoid this problem. See Section III-A-4.) Therefore, although the example above suggests a possible increase of up to $100 \%$ above the base case flow, this might not be achievable with switched capacitors alone.

3) Phase-Shifting Transformers: In (2), line power flow depends on the sin of the angle across the line. A phase-shifting transformer can alter this angle, consequently changing the amount of power flowing on the line. Similar to series compensation, this can be used to better utilize the thermal capacity of parallel lines [11]. In particular, inserting a phase-shift of $\Delta \delta$ changes the phase shift across the line to be $\delta+\Delta \delta$, modifying (2) to:

$$
\left|V_{s}\right|\left|V_{r}\right| \sin (\delta+\Delta \delta) / X
$$

which, for positive $\Delta \delta$, will increase the flow on the line for given sending and receiving end voltage magnitudes and given angle $\delta$. (Phase-shifting transformers are often used to reduce the flow on an otherwise over-loaded line; however, we will interpret the phase-shifting transformer as allowing for increased flow on another line.)

Again consider a 100 mile length of $345 \mathrm{kV}$ line that without the phase-shifting transformer had a flow equal to half of its rated capacity. Using (2) and the values calculated in Section III-A-2, this yields an angle difference across the line of approximately $17.5^{\circ}$, assuming that the voltage magnitudes are equal to their nominal values. To achieve a flow equal to the nominal thermal capacity would require an angle difference across the line of approximately $37^{\circ}$. That is, to increase the loading from being equal to one half the thermal capacity to being equal to the thermal capacity would require a phase-shifting transformer capable of achieving $\Delta \delta \approx 20^{\circ}$.

In [12], variable phase shifts from $-25^{\circ}$ to $25^{\circ}$ are described for phase-shifting transformers installed in the Western Interconnection. This capability is sufficient to achieve the increase described in the last paragraph. In [10, Table C-4-1], specific capacity costs of $\$ 25 / \mathrm{kVA}$ are given for phase-shifting transformers. Assuming a phase-shifting transformer rating equal to the line rating then the effective uprating cost for a 100 mile length of $345 \mathrm{kV}$ line is $\$ 500 / \mathrm{MW}$-mile.

The effective uprating costs for longer lines would be proportionally smaller. As with series compensation, this accounts for the greater prevalence of phase-shifting transformers in the Western Interconnection.

As with all mechanically switched devices, switching operations impose wear and tear. Consequently, the frequency of changes in phase-shift may be limited to reduce wear and tear. In some cases, a fixed phase-shift of, for example, $\pi / 6$ may be adequate and this can be accomplished with a star-delta transformer.

4) Flexible AC Transmission (FACTS): Flexible AC transmission systems involve the use of power semiconductors to switch powerline currents and voltages [7]. The most straightforward application involves thyristor switching of elements such as capacitors, reactors, and transformer taps; however, more complex designs including energy storage have been proposed and implemented in various applications. A number of example configurations are described in [7, Sec. 1.7]. 
Power semiconductors are able to switch more rapidly than mechanical switches and, moreover, do not typically have limits on the number of switching operations. Consequently, they can be used to control steady-state phenomena such as reactive power and also adapt to changes in the system. Moreover, they can also contribute to the stabilization of the system under transient conditions and contribute to:

- prevention of voltage instability by responding to depressed voltages with increased reactive output, and

- prevention of sub-synchronous resonance by detecting and damping out transients.

For example, if high levels of shunt or series capacitor compensation are required then FACTS devices may be necessary instead or in addition to mechanically switched capacitors.

Thyristor switched elements are typically more expensive than their mechanically switched counterparts. For example, in [10, Table C-4-1], the cost of mechanically switched capacitors is given as $\$ 15-25 / \mathrm{kVAr}$, while the cost of thyristor controlled series capacitors is given as $\$ 40-50 / \mathrm{kVar}$. That is, thyristor switching would approximately double the costs compared to mechanical switching, although the maximum level of compensation may then be higher than achievable with mechanical switching because of the ability to actively control and so avoid sub-synchronous resonance. Because of cost considerations, typical FACTS installations include a combination of mechanically and electronically switched elements. This means that the overall costs will typically fall in the range between the cost of mechanically switched compensation and double the cost of mechanically switched compensation. The entries in Table III reflect this.

In addition to providing electronically switched versions of mechanically switched shunt and series compensation and of phase-shifting transformers, power electronic devices can be arranged as active voltage sources [7]. In the absence of a source of real power, such a voltage source behaves similarly to a controllable capacitor or reactor. However, when two or more FACTS devices are linked together, real power can be transferred from one to the other. For example, one FACTS device might be in shunt and the other in series in a line. Real power can be taken by the shunt device from the line and injected by the series device back into the line. The effect is to control the flow of power along the line in ways that are not possible with shunt or series compensation alone. This extra degree of freedom offers flexibility, particularly in controlling transient phenomena. The value of this compensation and its ability to increase capacity is very dependent on the particular phenomena being addressed. Consequently, the uprating cost is likely to be very variable.

5) Insulating Spacers: The inductance of the line, and hence its steady-state stability limit, depends on the spacing of conductors. The spacing of the conductors must be such as to avoid flashover between phases at the operating voltage even if the conductors have swung towards each other. Long spans, particularly, present a problem in this regard since the conductors can swing much closer together at the center of the span than at the supporting towers. Insulating spacers can be used to limit the amount of swing in long spans. This can enable the conductors to be closer together on average, which decreases the inductance and increases the steady-state stability limit. The value of this enhancement is likely to be very specific to the situation, depending on, among other issues, the length of the longest span in the transmission line. For this reason, the uprating cost is very variable.

6) Circuit Breakers and Other Sub-Station Equipment: In some cases, transmission capacity may be limited by the ratings of circuit breakers and other sub-station equipment. Judicious uprating of this equipment can significantly uprate transmission capacity. Moreover, in most upgrades some uprating of sub-station equipment is likely to be necessary. We will not discuss this issue explicitly, except in the context of replacement by superconducting cable in Section III-B-2.

\section{B. Increasing Thermal Capacity}

In this section, we consider several ways to increase thermal capacity, by re-conductoring, replacement by superconducting cables, and line-tensioning devices.

1) Re-Conductoring: The resistance of aluminum conductor in a cable, and hence its thermal capacity, depends on the resistivity and cross-section of aluminum used. Towers and poles are typically sized for the weight of the cable and the wind-loading and snow-loading, which depend on the diameter of the cable. Most transmission lines in North America use "aluminum conductors, steel reinforced" (ACSR) cable. Most of the current flows in the aluminum, while the steel provides strength to prevent sagging of the conductor.

There are other types of cable developed that are designed to replace cable in an existing application with cable that has a higher current-handling capability [13]. For example:

- "aluminum conductor, steel supported" (ACSS, manufactured by Southwire and Alcan and which apparently has been in use for over a decade),

- "aluminum conductor, composite core" (ACCC, a recently developed cable that is manufactured by Composite Technology Corporation) [14], and

- "aluminum conductor, composite reinforced" (ACCR, another recently developed cable by 3M Corporation) [15].

ACSS uses fully annealed aluminum (instead of only partially annealed conductor) so that most of the weight of the cable is supported by the steel core. The lack of mechanical loading on the aluminum means that it can be operated at higher temperature without causing it to sag irreversibly.

ACCC uses a high strength, low density composite core instead of steel [14]. This allows for higher cross-sectional area of aluminum for a given total cross-sectional area and weight per unit length. High purity aluminum is used to decrease resistivity.

ACCR utilizes a core containing "aluminum oxide ceramic fibers embedded in pure aluminum" [15]. The core has similar strength properties to steel, but weighs similar to aluminum. The conductor strands are an aluminum-zirconium alloy that allows higher operating temperatures without softening.

To better utilize the available cross-sectional area of cable, the individual strands of the conductors can be manufactured with trapezoidal cross-section to increase the amount of conductor in a given cross-sectional area. The use of high purity aluminum (as in ACCC) and special alloys (as in ACCR) also improves the electrical or thermal characteristics. 
Re-conductoring can be extremely effective to increase the capacity of lower voltage lines since operation of such lines is often limited by the thermal rating and, moreover, older lower voltage lines may have been constructed with towers that can support higher weights of conductor enabling a very significant increase in current handling capacity through the use of the newer conductors. Re-conductoring is not effective for stability limited lines since the inductance is not changed significantly by re-conductoring.

For these cables, operating temperatures as high as $200{ }^{\circ} \mathrm{C}$, and in some cases above this temperature, are acceptable, assuming that the insulator strings and other nearby equipment can tolerate this temperature. In contrast, ACSR is typically limited to around $100^{\circ} \mathrm{C}$. The corresponding increase in the allowable temperature rise above ambient implies a corresponding increase in the current handling capability for a given cross-sectional area of a given conductor.

The cost of these cables is higher than conventional cables. In the case of trapezoidal conductors this is, in part, due to the larger amount of aluminum in the cable. The high purity and special alloy conductors are also more expensive than standard aluminum. The composite and ceramic cores are also presumably more expensive than steel. Moreover, re-conductoring involves permitting, engineering design, and labor costs in addition to the conductor cost. Assuming a cost of approximately $\$ 5 / \mathrm{ft}$ of cable, one mile of three-phase line would involve a conductor cost of approximately $\$ 80000$ [16].

Additional costs (including engineering design, permitting, legal costs, construction costs) have added another $\$ 200000$ to the cost of an initial installation [16]. However, some of these costs may be expected to be reduced in subsequent implementations. Moreover, the replaced conductor may have some salvage value. (Finally, it should be noted that in making comparisons to other uprating technologies, some of these additional costs may also be incurred for the other uprating technologies and may also be incurred for new lines, but may not be explicitly accounted for in the engineering estimates provided in [3]-[5].)

For the $138 \mathrm{kV}$ line described in Tables I and II, assuming that the cable enabled a doubling of the thermal capacity, the effective uprating cost is around $\$ 1500 / \mathrm{MW}$-mile, which is in the middle of the range of costs for new capacity reported in [3]. If the uprating costs were driven down to the cost of the conductor then the effective uprating costs would be around \$400/MW-mile.

For the $345 \mathrm{kV}$ line described in Tables I and II, and again assuming that the cable enabled a doubling of the thermal capacity at a conductor cost of $\$ 160000$ (each phase has two conductors "bundled" together accounting for the doubling in cable costs compared to the $138 \mathrm{kV}$ line) and $\$ 200000$ in other costs, the effective uprating cost would be around $\$ 300 / \mathrm{MW}$-mile. If the uprating costs were driven down to the cost of the conductor then the effective uprating costs would be around \$130/MW-mile.

2) Replacement by Superconducting Cable: Many cable tunnels in urban areas are reaching their capacity, while the ability to enlarge the cross-section of the tunnels is typically limited. Superconducting cables are being proposed for applications in such areas. Experimental implementations are being developed in New York, for example [17]. Cost estimates for commercial- scale implementations are not available, but are probably considerably higher than the cost of re-conductoring with high-capacity aluminum cables.

In some cases, however, fault levels may also limit the ability to increase capacity. An innovation with superconducting cables is the ability to control the threshold current level above which superconduction ceases. This allows for uprated current handling capacities, without necessarily increasing fault current levels [17]. In cases where fault current interruption capacity cannot be economically increased, superconducting cables may provide a path for uprating thermal capacity.

3) Line Tensioning Devices: As discussed above, as lines heat up, they lengthen and sag. Sometimes, the thermal limit is set by the clearances to objects below the line rather than being due to conductor temperature limits. In this case, a tensioning device [18] can be added to key spans to reduce the amount of sagging. There are several issues that affect the overall cost, including the following [19].

- The number of tensioning devices required for a span that is being tensioned. For example, in a horizontal conductor configuration, presumably all three phases would require tensioning and so three devices would be required in a span. On the other hand, in a vertical conductor configuration, it might be the case that only one or two tensioning devices would be required per span. An average of two devices for each span requiring tensioning was assumed in the calculations.

- The fraction of spans that require tensioning. In some cases, tensioning one span will also apply tension to adjacent spans. It may be possible to use tensioning devices on, for example, $10 \%$ to $25 \%$ of spans.

- The number of spans per mile.

- The increased thermal capacity that is available by allowing higher temperature operation of the conductor. We will assume a $15 \%$ upgrade in capacity.

Assuming a cost of $\$ 10000$ per tensioning device (including installation), an average of 0.2 to 0.5 devices per span, and six spans per mile on average yields an effective uprating cost of \$70-170/MW-mile [20], [21].

\section{Summary}

Table III summarizes the effective cost of uprating transmission capacity for various technologies. It should again be emphasized that these are rough estimates and that they may not be fully comparable. For example, some of the costs included in the re-conductoring cost may not have been represented appropriately for some of the other technologies nor in the cost estimates for new lines. As another example, the cost of line tensioning devices would be lower if only a small number of spans required modification to avoid clearance problems. Moreover, as discussed in Section I, these are circa 2005 costs.

As mentioned in Section II-B, [3] reports typical new construction costs in the range of $\$ 400 / \mathrm{MW}$-mile to $\$ 3000 / \mathrm{MW}$ mile for transmission lines operating at below $200 \mathrm{kV}$ and typical costs in the range of $\$ 400 / \mathrm{MW}$-mile to $\$ 1000 / \mathrm{MW}$-mile for transmission lines operating at above $200 \mathrm{kV}$. Comparing the uprating costs to the costs of new construction we observe that: 
TABLE III

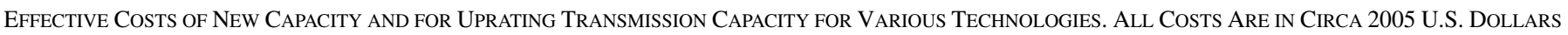

\begin{tabular}{|c|c|c|c|c|c|}
\hline Type & Technology & $\begin{array}{l}\text { Specific } \\
\text { cost }\end{array}$ & $\begin{array}{l}\text { Assumptions for effective } \\
\text { cost calculation, } \\
\text { base case operation }\end{array}$ & $\begin{array}{c}\text { Effective } \\
\text { cost } \\
\text { (\$/MW-mile) }\end{array}$ & $\begin{array}{c}\text { Additional } \\
\text { capacity } \\
\text { over base }(\%)\end{array}$ \\
\hline \multirow{2}{*}{$\begin{array}{l}\text { New } \\
\text { Capacity }\end{array}$} & $\begin{array}{l}\text { New } \\
\text { transmission }\end{array}$ & $\begin{array}{l}\text { \$400/MW-mile to } \\
\text { \$3000/MW-mile }\end{array}$ & $\begin{array}{l}\text { Below 200kV } \\
\text { operation }\end{array}$ & 4400-3000 & NA \\
\hline & $\begin{array}{l}\mathrm{New} \\
\text { transmission }\end{array}$ & $\begin{array}{l}\text { \$400/MW-mile to } \\
\text { \$1000/MW-mile }\end{array}$ & $\begin{array}{l}\text { Above } 200 \mathrm{kV} \\
\text { operation }\end{array}$ & $400-1000$ & NA \\
\hline \multirow{8}{*}{$\begin{array}{l}\text { Increased } \\
\text { utilization }\end{array}$} & $\begin{array}{l}\text { Shunt capacitive } \\
\text { compensation } \\
\text { (switched) }\end{array}$ & $\begin{array}{l}\$ 10 / \mathrm{kVAr} \text { to } \\
\$ 50 / \mathrm{kVAr}\end{array}$ & $\begin{array}{l}0.9 \text { power factor, } \\
100 \text { mile length }\end{array}$ & $200-1000$ & $5-10$ \\
\hline & $\begin{array}{l}\text { Series capacitive } \\
\text { compensation } \\
\text { (switched) }\end{array}$ & $\begin{array}{l}\text { \$15/kVAr to } \\
\$ 60 / \mathrm{kVAr}\end{array}$ & $\begin{array}{l}345 \mathrm{kV} \text { line operated } \\
\text { at half thermal capacity, } \\
100 \text { mile length }\end{array}$ & $45-180$ & $<100$ \\
\hline & $\begin{array}{l}\text { Phase-shifting } \\
\text { transformer } \\
\text { (switched) }\end{array}$ & $\$ 25 / \mathrm{kVA}$ & $\begin{array}{l}345 \mathrm{kV} \text { line operated } \\
\text { at half thermal capacity, } \\
100 \text { mile length }\end{array}$ & 500 & 100 \\
\hline & $\begin{array}{l}\text { Shunt capacitive } \\
\text { compensation } \\
\text { (FACTS) }\end{array}$ & $\begin{array}{l}\text { \$10/kVAr to } \\
\$ 50 / \mathrm{kVAr}\end{array}$ & $\begin{array}{l}0.9 \text { power factor, } \\
100 \text { mile length }\end{array}$ & $200-2000$ & $5-10$ \\
\hline & $\begin{array}{l}\text { Series capacitive } \\
\text { compensation } \\
\text { (FACTS) }\end{array}$ & $\begin{array}{l}\$ 20 / \mathrm{kVAr} \text { to } \\
\$ 60 / \mathrm{kVAr}\end{array}$ & $\begin{array}{l}345 \mathrm{kV} \text { line operated } \\
\text { at half thermal capacity, } \\
100 \text { mile length }\end{array}$ & $60-360$ & 100 \\
\hline & $\begin{array}{l}\text { Phase-shifting } \\
\text { transformer } \\
\text { (FACTS) }\end{array}$ & $\$ 25 / \mathrm{kVA}$ & $\begin{array}{l}345 \mathrm{kV} \text { line operated } \\
\text { at half thermal capacity, } \\
100 \text { mile length }\end{array}$ & 1000 & 100 \\
\hline & $\begin{array}{l}\text { Insulating } \\
\text { spacers }\end{array}$ & & $\begin{array}{l}\text { difficult to } \\
\text { characterize }\end{array}$ & & \\
\hline & $\begin{array}{l}\text { Substation } \\
\text { upgrades }\end{array}$ & & $\begin{array}{l}\text { difficult to } \\
\text { characterize }\end{array}$ & & \\
\hline \multirow{4}{*}{$\begin{array}{l}\text { Increased } \\
\text { thermal } \\
\text { capacity }\end{array}$} & $\begin{array}{l}\text { Re-conductoring } \\
\text { with } \\
\text { ACCC cable }\end{array}$ & $\$ 5 /$ foot & $\begin{array}{l}\$ 0-200 \mathrm{k} \text { additional costs } \\
\text { per mile, doubling } \\
138 \mathrm{kV} \text { thermal capacity }\end{array}$ & $400-1500$ & 100 \\
\hline & $\begin{array}{l}\text { Re-conductoring } \\
\text { with } \\
\text { ACCC cable }\end{array}$ & $\$ 5 /$ foot & $\begin{array}{l}\$ 0-200 \mathrm{k} \text { additional costs } \\
\text { per mile, doubling } \\
345 \mathrm{kV} \text { thermal capacity }\end{array}$ & $130-300$ & 100 \\
\hline & $\begin{array}{l}\text { Replacing with } \\
\text { superconductor }\end{array}$ & & $\begin{array}{l}\text { difficult to } \\
\text { characterize }\end{array}$ & & \\
\hline & $\begin{array}{l}\text { Line } \\
\text { tensioning } \\
\text { devices }\end{array}$ & $\begin{array}{l}\$ 10,000 \text { per } \\
\text { tensioning } \\
\text { device }\end{array}$ & $\begin{array}{l}345 \mathrm{kV} \text { line, average } 0.2-0.5 \\
\text { devices per span, } \\
6 \text { spans per mile }\end{array}$ & $70-170$ & 15 \\
\hline
\end{tabular}

- the uprating costs for shunt capacitive compensation, re-conductoring of $138 \mathrm{kV}$ lines, and phase-shifting transformers overlap the range of costs for new construction but are typically at the low end of the range, while

- the uprating costs for series capacitive compensation, line tensioning devices, and re-conductoring of $345 \mathrm{kV}$ line are strictly below the ranges of costs for new construction.

\section{CONCLUSION}

There are a number of established and emerging technologies available for uprating the capacity of transmission lines. Their costs overlap or are lower than typical costs of new construction. In regions where high land costs drive extremely high costs of new transmission construction, uprating technologies are likely to be competitive or superior on a cost basis compared to new construction.

\section{ACKNOWLEDGMENT}

The authors would like to thank L. Barroso, R. Gray, D. Shirmohammadi, M. Shirmohamadi, and P. vanMidde for discussions about and feedback on this work.

\section{REFERENCES}

[1] A. R. Bergen and V. Vittal, Power Systems Analysis, 2nd ed. Upper Saddle River, NJ: Prentice-Hall, 2000.

[2] R. D. Dunlop, R. Gutman, and P. P. Marchenko, "Analytical development of loadability characteristics for EHV and UHV transmission lines," IEEE Trans. Power App. Syst., vol. PAS-98, no. 2, pp. 606-617, Mar./Apr. 1979.

[3] K. Dixit and R. Baldick, "An empirical study of the economies of scale in AC transmission line construction costs," Dec. 2003, unpublished manuscript.

[4] "Valuation of electricity network assets: A policy guideline for New South Wales distribution network service," New South Wales Treasury, Australia, Tech. Rep., Feb. 2004.

[5] "Investment costs spreadsheet," Transmission Service Development, ISA, Colombia, Tech. Rep., Aug. 2004.

[6] L. A. Barroso, F. Porrua, L. M. Thomé, and M. V. Pereira, "Planning big things in Brazil," IEEE Power Energy Mag., vol. 5, no. 5, pp. 54-63, Sep./Oct. 2007.

[7] N. G. Hingorani and L. Gyugyi, Understanding FACTS. New York: IEEE Press, 2000.

[8] Power Circuit Breaker Theory and Design, C. H. Flurscheim, Ed. U.K.: Inst. Elect. Eng., 1982.

[9] R. Baldick, "Reactive issues: Reactive power in restructured markets," IEEE Power Energy Mag., vol. 2, no. 6, pp. 14-17, Nov./Dec. 2004.

[10] California Independent System Operator, "1998 transmission reliability report.” Tech. Rep., 1998. [Online]. Available: www.caiso.com. 
[11] R. Baldick and E. Kahn, "Contract paths, phase-shifters, and efficient electricity trade," IEEE Trans. Power Syst., vol. 12, no. 2, pp. 749-755, May 1997.

[12] J. Bladow and A. Montoya, "Experiences with parallel EHV phase shifting transformers," IEEE Trans. Power Del., vol. 6, no. 3, pp. 1096-1100, Jul. 1991.

[13] W. D. Jones, "More heat, less sag," IEEE Spectr., vol. 43, no. 6, pp. 16-18, Jun. 2006.

[14] Composite Technology Corporation, "Innovative solutions for the power industry." [Online]. Available: www.compositetechcorp.com/compbroch.pdf. 2000.

[15] "Aluminum Conductor Composite Reinforced Product Data and Design Guides," 2007. [Online]. Available: solutions.3m. com/wps/portal/3M/en\_US/Energy-Advanced/Materials/Resources/MMC/ACCR/Design\_Guide/, 3M Corp., webpage.

[16] P. vanMidde, personal communication, 2004.

[17] American Superconductor Corp., "Secure super grids: A new solution for secure electric power in critical urban centers." 2007, unpublished manuscript.

[18] The sagging line mitigator (SLiM) 2003, Material Integrity Solutions, Inc., product description.

[19] R. Gray, personal communication, 2006.

[20] M. Shirmohamadi, personal communication, 2006, SLIM cost \$/MWmile.
[21] M. Shirmohamadi, personal communication, 2007, SLIM cost \$/MWmile.

Ross Baldick (F'07) received the B.Sc. degree in mathematics and physics and the B.E. degree in electrical engineering from the University of Sydney, Sydney, Australia, and the M.S. and Ph.D. degrees in electrical engineering and computer sciences from the University of California, Berkeley, in 1988 and 1990, respectively,

From 1991 to 1992, he was a Postdoctoral Fellow at the Lawrence Berkeley Laboratory. In 1992 and 1993, he was an Assistant Professor at Worcester Polytechnic Institute, Worcester, MA. Currently, he is a Professor in the Department of Electrical and Computer Engineering at The University of Texas at Austin.

Richard P. O'Neill received the Ph.D. degree in operations research from the University of Maryland, College Park.

Currently, he is Chief Economic Advisor in the Federal Energy Regulatory Commission Office of Markets, Tariffs, and Rates. He was previously on the faculty of the Department of Computer Science at Louisiana State University, Baton Rouge, and on the faculty of the Business School at the University of Maryland, College Park. 